\title{
Desenvolvimento de uma escala para medir o potencial empreendedor utilizando a Teoria da Resposta ao Item (TRI)
}

\author{
Development of a scale to measure the entrepreneurial \\ potential using the Item Response Theory (IRT)
}

\author{
Luciano Ricardo Rath Alves ${ }^{1}$ \\ Antonio Cezar Bornia ${ }^{1}$
}

\begin{abstract}
Resumo: Diversas variáveis estão relacionadas ao desenvolvimento da atividade empreendedora, verifica-se, entre elas, a importância do agente empreendedor. Dos estudos que contribuem para o seu entendimento, este segue a linha que defende que o empreendedor tem características e traços de personalidade singulares em relação à população, os quais são propícios ao sucesso do empreendedorismo. O objetivo deste trabalho é desenvolver uma escala para medir o potencial empreendedor utilizando a Teoria da Resposta ao Item. Foi utilizado o modelo logístico de dois parâmetros da TRI. As estimativas dos parâmetros foram obtidas a partir da amostra com 764 pessoas que responderam a um instrumento composto por 103 itens. A curva de informação e do erro padrão do teste e a interpretação qualitativa de níveis da escala permitiram determinar o intervalo mais apropriado para utilização do instrumento. Os resultados mostraram que a escala é mais adequada para avaliar indivíduos com baixo até moderadamente alto potencial empreendedor. Por isso, sugere-se que novos itens sejam incorporados ao instrumento para mensurar e interpretar níveis ainda mais elevados. A Teoria da Resposta ao Item permite que novos itens sejam calibrados a fim de mensurar os empreendedores com alto potencial empreendedor, aproveitando os dados já obtidos.
\end{abstract}

Palavras-chave: Potencial empreendedor. Empreendedor. Escala. Teoria da Resposta ao Item (TRI).

\begin{abstract}
Several variables are related to the development of entrepreneurial activities. An important one among them is the entrepreneurial agent. This study is one of many that contribute to the understanding of the entrepreneurial agent. In its line of thought, it upholds the idea that the entrepreneur has characteristics and personality traits that stand out from the general population and that are favorable to the success of the entrepreneurship. This study aims at developing a measurement scale for entrepreneurial potential using the Item Response Theory. The items were generated by Santos (2008) based on a theoretical model referenced in theories of entrepreneur's personality. The samples include 664 undergraduate and graduate students of Brazilian universitie, and 100 entrepreneurs of the state of Alagoas. A two-parameter logistic IRT model was used. The parameter estimates were obtained from a sample of 764 people who responded to an instrument containing 103 items. The information and the standard error curves and the qualitative interpretation of the scale levels allowed us to determine the most appropriate range for the instrument use. The results showed that the scale is most adequate to evaluate individuals with low to moderately high entrepreneurial potential. Therefore, it is suggested that new items are incorporated into the instrument to measure and interpret even higher levels. The Item Response Theory allows the calibration of new items to measure entrepreneurs with high entrepreneurial potential using previously obtained data.
\end{abstract}

Keywords: Potential entrepreneur. Entrepreneur. Scale. Item Response Theory. IRT.

\section{Introdução}

Considerando o trabalho de Cantillon publicado em 1755 como precursor do estudo do empreendedor (MURPHY; LIAO; WELSH, 2006) há mais de dois séculos, estudiosos de diferentes áreas do conhecimento fazem conjecturas e fundamentações a fim de descrever este agente. Cada pesquisador, sob a ótica do seu domínio epistêmico, encontra um ou mais aspectos potencialmente relevantes relacionados ao ato de uma pessoa embrenhar-se no empreendedorismo e de encontrar sucesso nesta ação. Alguns aspectos são exógenos à figura do empreendedor como a cultura em que se inserem, os incentivos institucionais e as

\footnotetext{
${ }^{1}$ Programa de Pós-graduação em Engenharia de Produção - PPGEP, Universidade Federal de Santa Catarina - UFSC, Centro Tecnológico - CTC, Campus Universitário, Trindade, CP 476, CEP 88040-900, Florianópolis, SC, Brasil e-mails: lucianorath@yahoo.com.br; cezar@deps.ufsc.br

Recebido em 31/8/2010 - Aceito em 10/8/2011
}

Suporte financeiro: CNPq. 
condições micro e macroeconômicas. Outros são inerentes à natureza humana, explicados por diferentes correntes e conceitos da psicologia. A amplitude destes estudos, ao mesmo tempo em que gera posições controversas, enriquece a discussão e a compreensão do tema. Filion (2000), por exemplo, menciona ter reunido mais de 100 definições de empreendedor e empreendedorismo, das quais sintetiza que:

O empreendedor é com frequência considerado uma pessoa que sabe identificar as oportunidades de negócios, os nichos do mercado e que sabe se organizar para progredir. Assim, a essência do trabalho do empreendedor consiste em definir contextos, o que exige uma análise e imaginação, um equilíbrio entre as funções do lado direito e do lado esquerdo do cérebro. (FILION, 2000, p. 14).

A importância do empreendedor para o desenvolvimento socioeconômico tem sido defendida por autores renomados há bastante tempo. No início do século XX, Schumpeter enfatizou a função deles na geração de uma alteração criativa na economia (MURPHY; LIAO; WELSH, 2006). Na década de 1960, McClelland (1968) defendeu que o desenvolvimento das nações se dava pela necessidade de realização de seu povo, destacando as ações dos empreendedores neste processo. Nessa mesma década, Maslow (2001, p. 265) afirmou que a

"[...] diferença entre as grandes e boas sociedades e as sociedades em regressão está na oportunidade empreendedora e no número de empreendedores existentes na sociedade."

Segundo Acs, Desai e Hessels (2008), nos últimos anos, explodiu a consciência da importância econômica atribuída aos empreendedores. Acs (2007) cita que empreendedores geram empregos e inovações e intensificam a competitividade, de forma que níveis elevados de empreendedorismo por oportunidade refletem em crescimento econômico.

Este é um trabalho psicométrico, fundamentado em teorias e estudos de características e traços de personalidade do empreendedor e na Teoria da Medida. O objetivo é desenvolver uma escala para medir o potencial empreendedor utilizando a Teoria da Resposta ao Item.

O presente trabalho está estruturado em 7 seções. A primeira introduz a importância do empreendedorismo, em especial do empreendedor, para o desenvolvimento socioeconômico, as teorias que fundamentam o artigo e o objetivo do trabalho. A seção 2 resgata teorias e estudos sobre características e traços da personalidade do empreendedor. A seção 3 mostra trabalhos realizados para medir características do empreendedor. A seção 4 expõe o embasamento da Teoria da Resposta ao Item. Os procedimentos metodológicos estão descritos na seção 5. Na seção 6, tem-se o desenvolvimento da escala do potencial empreendedor. Por fim, na seção 7, expõem-se as conclusões e recomendações.

\section{A personalidade do empreendedor}

A definição de personalidade é algo complexo na psicologia, uma vez que profissionais desta área a percebem sob óticas diferentes. Rotter e Hochreich (1980, p. 1) afirmam que, de forma geral:

[...] o termo é empregado para referir-se às características individuais, modos relativamente estáveis de pensar, perceber, e comportar-se, excluindo somente aquelas características estáveis que englobam níveis de inteligência ou aptidões intelectuais (ou seja, aqueles comportamentos que são mensurados através de testes padronizados de inteligência geral, realização ou aptidão).

Uma corrente teórica enfatiza o estudo da personalidade do empreendedor, procurando características e traços que descrevam o seu comportamento (ASLETE, 2008; BRASDSTÄTTER, 1997; McCLELLAND et al., 1987; LEZANA; TONELLI, 2004; LITTUNEM, 2000; MORALES, 2004).

Santos (2008) aduz que traços e características dos empreendedores ora são defendidos, ora criticados na literatura. Segundo o mesmo autor, pesquisas recentes são favoráveis em afirmar que os empreendedores têm traços de personalidades singulares em relação ao restante da população.

Para Lezana e Tonelli (2004, p. 39):

A personalidade do empreendedor tem um impacto decisivo na nova firma. [...] A personalidade do empreendedor configurará a imagem da empresa, os valores e o comportamento da firma.

Desta forma, este trabalho segue a linha de pesquisa que relaciona personalidade ao potencial empreendedor. As subseções seguintes fundamentam alguns estudos e teorias condizentes com esta corrente de pesquisa. São elas: Necessidade de Realização de McClelland, Autoeficácia Percebida de Bandura, Aprendizado Social e Lócus de Controle de Rotter, Comportamento Planejado de Ajzen, Tipos de Empreendedor de Miner e Comportamento do Empreendedor de Lezana e Tonelli.

\subsection{A necessidade de realização de McClelland}

David McClelland (1968) fez reflexões críticas acerca das teorias que tentavam esclarecer o desenvolvimento econômico dos povos ao longo da história (habilidade de guerrear e de governar, clima, 
posição geográfica etc.). Com sua formação em psicologia, acreditava ser uma parcimônia explicar que tal desenvolvimento dava-se pela necessidade de realização das pessoas. Para defender sua tese, realizou estudos na década de 1960 envolvendo crianças (e suas histórias infantis), jovens e empresários de diferentes países, que constataram haver relação entre o desenvolvimento econômico e a necessidade de realização. Segundo Morales (2004), estudos de McClelland inferiram que empreendedores de sucesso têm alta necessidade de realização.

\subsection{A Teoria da Autoeficácia Percebida (TAP) de Bandura}

Conforme Bandura (1997), as pessoas empenham-se em controlar os eventos que afetam a sua vida. A falta de experiência e habilidade para desempenhar este controle gera apreensão, apatia ou desespero, enquanto que a capacidade de produzir resultados positivos estimula o desenvolvimento e o exercício do controle pessoal. O impacto da eficácia pessoal depende dos fins a que se propõe alcançar. Para a TAP, as motivações, tomadas de decisões e ações estão calçadas mais nas crenças do que os indivíduos podem fazer do que naquilo que objetivamente podem fazer.

Entre os mecanismos psicossociais da ação humana, nenhum é mais central ou sagaz que as crenças na sua própria eficácia. A autoeficácia percebida refere-se às crenças de cada um quanto às capacidades de organizar e executar as ações requeridas em situações prospectivas. Estas crenças influenciam como as pessoas pensam, sentem, motivam-se etc. (BANDURA, 1997, p. 2, tradução nossa).

Estudos que evidenciaram positivamente a relação entre a performance do empreendedor e a autoeficácia percebida podem ser encontrados em Chen, Greene e Crick (1998); Hmielesc e Corbertt (2008); Markman e Baron (2003).

\subsection{A Teoria do Aprendizado Social (TAS) e do Lócus de Controle de Rotter}

Segundo Rotter e Hochreich (1980), a TAS advoga que a personalidade é formada por um conjunto de potencialidades para responder a situações diferentes. Desta forma, a personalidade e as interações com o meio influenciam-se reciprocamente. $\mathrm{O}$ comportamento é regido pela lei do reforço. Para aqueles autores, suprir uma necessidade implica em: (i) identificar um conjunto de comportamentos dirigidos a algum objetivo; (ii) atribuir valor e escolher uma entre as alternativas; e (iii) ter expectativas de que será capaz de atingir o objetivo valorizado.
Derivado da TAS, o lócus de controle refere-se às expectativas generalizadas de quem ou o quê pode resolver os problemas de um indivíduo. Pessoas com alto lócus de controle interno acreditam na sua habilidade e no seu esforço, em detrimento de ações de agentes externos ou de situações casuais (ROTTER; HOCHREICH, 1980).

O lócus de controle é uma teoria que tem despertado grande interesse no estudo do empreendedor (HANSEMARK, 1998). Brockhaus (1980) encontrou maior lócus de controle interno em empreendedores de sucesso em relação àqueles que não obtiveram êxito nesta atividade. Shane, Locke e Collins (2003) citam um trabalho realizado por Shapero de 1977 que encontrou maior lócus de controle interno nas pessoas que se aventuraram a fundar empresas do que em outras com diferentes profissões. Cai, Yin e Zhang (2008) relatam que na China há um elevado índice de atividade e sobrevivência de empreendimentos. $\mathrm{O}$ estudo daqueles autores observou que

[...] empreendedores com lócus de controle interno tendem a adotar estratégias inovadoras e ações proativas. (CAY; YANG; ZHANG, p. 1390, tradução nossa).

O estudo de Pandey e Tewary (1979), para uma corporação financeira da Índia, deu indícios de que pessoas que apresentam maior necessidade de realização e lócus de controle interno têm maiores chances de serem aprovadas em entrevistas de seleção para empreendedores.

\subsection{A Teoria do Comportamento Planejado (TCP) de Ajzen}

A teoria do comportamento planejado é uma extensão da teoria da ação racional de Ajzen e Fishbein de 1980 (AJZEN, 1991). A TCP enfatiza a intenção que o indivíduo tem para realizar um determinado comportamento. A intenção é influenciada pela atitude em relação ao comportamento, por normas subjetivas e pelo controle do comportamento percebido. A atitude em relação ao comportamento é vista como um juízo de valor do quão benéfico ou prejudicial o comportamento pode ser. Normas subjetivas referem-se às pressões sociais percebidas pelo sujeito. $\mathrm{O}$ controle do comportamento percebido é uma avaliação subjetiva da possibilidade de obter sucesso com o comportamento intentado, compreende habilidades, recursos, oportunidades, entre outros aspectos (AJZEN, 1991; FAYOLLE; GAILLY, 2004).

\subsection{Os tipos de empreendedor de Miner}

Outra linha de pesquisa do estudo da personalidade do empreendedor trata das diferenças entre elas - as tipologias. Para Miner (1996), apesar de estudos 
iniciados na década de 1960 sobre a relação entre a personalidade do empreendedor e o sucesso do empreendimento não serem conclusivos, a ponto de Guth em 1991 sugerir outras linhas de pesquisa como sendo mais promissoras, o tema continuou a intrigar os pesquisadores nos anos subsequentes.

Miner (1996) defendeu a hipótese de que a dificuldade de encontrar uma resposta satisfatória para explicar a personalidade empreendedora deve-se ao fato dos autores considerarem um 'estilo de empreendedor universal'.

Ao aplicar 17 testes psicológicos num grupo de cem empreendedores, Miner (1996) encontrou quatro tipos com traços de personalidades diferentes: (i) Realizadores: motivados pela autorrealização, têm necessidades de planejar, criar metas e obter feedback; têm forte iniciativa, acreditam no potencial das pessoas e que o trabalho deve ser guiado por objetivos pessoais; (ii) Super Vendedores Empáticos: são empáticos, sociáveis; prestativos e creem no processo de venda como crucial para a empresa; (iii) Gerentes Autênticos: são líderes, decisivos, competitivos, desejam o poder e destacar-se na multidão; (iv) Geradores de Inovações: possuem desejo e paixão por inovações, creem na importância de novos produtos, são inteligentes e evitam riscos. Complementa Miner (1996) que empreendedores geralmente acumulam mais de um tipo.

\subsection{O comportamento do empreendedor de Lezana e Tonelli}

Lezana e Tonelli $(2004$, p. 21) relacionam o comportamento empreendedor aos conceitos da psicanálise:

[...] as pessoas estruturam sua personalidade à medida que vivenciam as diferentes fases da vida [...] a criação de uma nova empresa e sua operação podem ser tratadas como oportunidade de satisfazer as necessidades do indivíduo. (p. 30).

As características da personalidade que determinam o comportamento são as necessidades (associadas ao Id); o conhecimento e as habilidades (ao Ego); e os valores (ao Superego). Os valores individuais adquiridos da sociedade, às vezes de forma inconsciente, norteiam ou até mesmo bloqueiam as decisões do empreendedor. O conhecimento e as habilidades geram o rol de alternativas que podem facilitar a intermediação, mais ou menos conflituosa, entre as necessidades e os valores no processo de decisão.

Lezana e Tonelli (2004) aduzem que o sucesso de um empreendimento dá-se pelo equilíbrio de fatores internos e externos do empreendedor. Para Lezana e Tonelli (2004, p. 40):
[...] estudos recentes demonstram que, apesar da variedade de fatores que levam a empresa ao sucesso, quase todos estão ligados à figura do empreendedor [...]. O que o torna diferente são as características de sua personalidade [...].

\subsection{Modelo de potencial empreendedor utilizado}

Este trabalho limitou-se a descrever algumas linhas de pesquisa de traços e características de empreendedores a fim de fundamentar o modelo teórico de potencial empreendedor empregado, o qual segue a corrente da Necessidade de Realização de David McClelland. McClelland, além de ser um pioneiro e um dos mais influentes pesquisadores da área (CORNELIUS; LANDSTRÖM; PERSON, 2006; van EMMERIK et al., 2010), teve seu trabalho revertido em programas de capacitação respaldados pela Organização das Nações Unidas (ONU), os quais vêm contribuindo para o desenvolvimento da atividade em diversos países (UNITED..., 2005; SANTOS, 2008).

\section{Mensuração do potencial empreendedor}

O Quadro 1 mostra algumas técnicas qualiquantitativas utilizadas para mensurar o potencial empreendedor de uma amostra de publicações:

Foram encontradas duas escalas de medida produzidas por pesquisadores brasileiros associadas às características do empreendedor. A escala de Santos (2008) enfatiza a teoria de McClelland e utiliza técnicas estatísticas de alfa de Cronback e análise fatorial para mensurar o potencial empreendedor; e a escala de Lopes Junior e Souza (2005) se baseia na Teoria do Comportamento Planejado e usa técnicas de análise fatorial para medir a atitude empreendedora. Inácio Júnior e Gimenez (2004) traduziram, validaram e aplicaram no Brasil o Carland Entrepreneurship Index $(C E I)$.

Não foi encontrada aplicação da TRI associada à mensuração de características de empreendedores e potenciais empreendedores numa pesquisa feita nas bases de periódicos da Capes: Scopus, Web of Science e ScienceDirect com a combinação de dois termos, sendo o primeiro 'item response theory' ou IRT e o segundo entrepreneur, entrepreneurial ou entrepreneurship.

\section{A Teoria da Resposta ao Item (TRI)}

“A TRI é um conjunto de modelos matemáticos que procura representar a probabilidade de um indivíduo dar uma certa resposta a um item como função dos parâmetros do item e da habilidade [ou habilidades] do respondente" (ANDRADE; TAVARES; VALLE, 2000, p. 7). 
Quadro 1. Técnicas quali-quantitativas utilizadas na pesquisa de características empreendedoras.

\begin{tabular}{|c|c|c|}
\hline Pesquisador (es) & Características & Técnicas utilizadas \\
\hline Koen et al. (2001) & Habilidades cognitivas & Correlação, regressão \\
\hline Hoen et al. (2002) & Persuasão e habilidades sociais & Análise fatorial, variância e teste $\mathrm{t}$ \\
\hline Smith (2002) & Propagação de valores & Histórias \\
\hline Ucbasaran e Westhead (2002) & Identificação de oportunidades & Análise fatorial, variância \\
\hline Baum, Bird e Chardavoyene (2003) & Inteligência prática & SEM \\
\hline Kikul e Gundry (2002) & Personalidade proativa & $\begin{array}{l}\text { Correlação, regressão, análise } \\
\text { fatorial }\end{array}$ \\
\hline Phan, Wong e Wang (2002) & Crenças, propensão a aprender & $\begin{array}{l}\text { Correlação, regressão, análise } \\
\text { fatorial }\end{array}$ \\
\hline $\begin{array}{l}\text { Schimitt-Rodermund e Vondraceck } \\
(2002)\end{array}$ & Propensão a aprender & Correlação, regressão \\
\hline Stewart Junior et al. (2003) & $\begin{array}{l}\text { Necessidade de realização, } \\
\text { propensão a lidar com riscos e } \\
\text { preferência por inovação }\end{array}$ & Correlação, regressão \\
\hline Luthans e Ibrayeva (2006) & Autoeficácia & SEM \\
\hline Gurol e Atsan (2005) & $\begin{array}{l}\text { Propensão ao risco, tolerância à } \\
\text { ambiguidade, locus de controle, } \\
\text { necessidade de realização, inovação, } \\
\text { autoconfiança }\end{array}$ & Teste $\mathrm{t}$ \\
\hline Beugelsdijk e Noorderhaven (2005) & Responsabilidade, esforço & Regressão \\
\hline Brollo $(2006)$ & $\begin{array}{l}\text { Competitividade, autonomia, } \\
\text { realização, mudança e autoeficácia . }\end{array}$ & Análise fatorial \\
\hline Wong, Cheung e Venuvinod (2005) & & Regressão, análise fatorial \\
\hline Korunga et al. (2003) & $\begin{array}{l}\text { Necessidade de realização, } \\
\text { propensão a riscos, iniciativa, locus } \\
\text { de controle, e autorrealização }\end{array}$ & Análise fatorial \\
\hline Envick e Langord (2003) & $\begin{array}{l}\text { Neuroticismo (ajustamento), } \\
\text { extroversão (sociabilidade), } \\
\text { consciência, afabilidade e franqueza }\end{array}$ & Variância \\
\hline Lopes Junior e Sousa (2005) & $\begin{array}{l}\text { Realização, planejamento, poder e } \\
\text { inovação }\end{array}$ & Análise fatorial \\
\hline Moriano, Sánches e Palací (2004) & $\begin{array}{l}\text { Valores, autoeficácia, riscos, locus } \\
\text { de controle }\end{array}$ & $\begin{array}{l}\text { Não informado, aparentemente } \\
\text { teste t }\end{array}$ \\
\hline
\end{tabular}

Fonte: SANTOS (2008, p. 127).

A TRI surgiu para suprir algumas limitações da Teoria Clássica da Medida (TCM) (PASQUALI; PRIMI, 2003). Entre as vantagens da TRI sobre a TCM, apontam-se: a TRI importa-se com a análise de cada item e não com a do teste como um todo (ANDRADE; TAVARES; VALLE, 2000; ANDREOLA, 2009); características do item são independentes da amostra dos sujeitos (EMBRETSON; REISE, 2000); o modelo não exige formas rigorosamente paralelas para avaliar a fidedignidade (PASQUALI; PRIMI, 2003); pode mensurar indivíduos submetidos a testes parcialmente diferentes e os mesmos indivíduos submetidos a testes totalmente diferentes (ANDRADE; TAVARES; VALLE, 2000); o erro padrão da medida é diferente para cada nível do traço latente (EMBRETSON; REISE, 2000); a dificuldade do item está na mesma escala da habilidade, o que implica que os escores dos respondentes têm significados quando se comparam suas posições em relação aos itens (EMBRETSON; REISE, 2000).

Pasquali (2003) considera que os primeiros testes para mensurar aptidões humanas foram realizados por Galton em 1883. Em 1905, Binet e Simon criam o teste de inteligência associado à idade mental com 30 itens (o qual pouco mais tarde viria a se tornar o teste de Q.I.). Sperman, nessa época, gera os fundamentos da TCM. A análise fatorial data da década de 1930, tendo como expoente o norte-americano Thurstone. Para van der Linden e Hambleton (1997), Thurstone, em 1927, ao utilizar o modelo de distribuição normal em uma escala de dispersão, lançou a base para a o primeiro modelo matemático da TRI - o modelo de ogiva normal. Segundo Andrade, Tavares e Valle (2000), Lord, em 1952, desenvolveu o primeiro modelo unidimensional de dois parâmetros baseado na distribuição normal acumulada (ogiva normal), 
obtendo uma função descrita pelos parâmetros dos itens e pela habilidade dos respondentes, o qual teve o modelo substituído pelo logístico de dois parâmetros (ML2) por Birnbaum em 1968.

Andrade, Tavares e Valle (2001) informam que a escolha do modelo da TRI depende fundamentalmente da natureza do item (dicotômico ou não dicotômico, ordinal ou nominal), do número de populações envolvidas (uma ou mais de uma) e da quantidade de traços latentes que se está medindo (modelos unidimensionais ou multidimensionais). Para Embretson e Reise (2000), a escolha do modelo depende do peso de cada item, das propriedades desejadas da escala e do tipo dos dados.

Para o desenvolvimento da escala proposta, este trabalho utiliza itens dicotomizados, amostra de duas populações - estudantes e empreendedores -, assume unidimensionalidade e não admite a existência de respostas ao acaso. Estas considerações levaram à escolha do modelo logístico de dois parâmetros da TRI.

O ML2 baseia-se na hipótese de que indivíduos com maior traço latente apresentam maior probabilidade de dar uma resposta afirmativa ao item (ANDRADE; TAVARES; VALLE, 2000).

O ML2 supõe unidimensionalidade e independência local. Segundo Pasquali (2003, p. 104), o postulado da independência local afirma que

[...] mantidas constantes as aptidões que afetam o teste, menos o traço latente dominante, as respostas dos sujeitos a quaisquer dos itens são estatisticamente independentes.

A única dimensão a ser medida é o potencial empreendedor.

A Equação 1 mostra a função matemática do ML2. Nela: $U_{\mathrm{ij}}$ representa a resposta dicotômica (valores 0 ou 1 ) do indivíduo $\mathrm{j}$ dada ao item $\mathrm{i}$; $\theta_{\mathrm{j}}$ é o potencial empreendedor do respondente $\mathrm{j}$; $\mathrm{P}\left(\mathrm{U}_{\mathrm{ij}}=1 \mid \theta_{\mathrm{j}}\right)$, a probabilidade do respondente $\mathrm{j}$ com o potencial empreendedor $\theta_{\mathrm{j}}$ apresentar o requisito questionado pelo item (valor igual a 1); $b_{i}$ é o parâmetro de dificuldade do item posicionado na mesma escala do potencial empreendedor (observa-se que $\left.\mathrm{P}\left(\mathrm{U}_{\mathrm{ij}}=1 \mid \theta_{\mathrm{i}}=b_{\mathrm{i}}\right)=0,5\right)$; e $\mathrm{a}_{\mathrm{i}}$ é o parâmetro de discriminação do item, equivalente à tangente da Curva Característica do Item (CCI) no ponto de inflexão da curva (em que $b_{i}=\theta_{j}$ ). O parâmetro 'a' tem a propriedade de conferir qualidade ao item. Valores baixos de 'a' conferem pouca capacidade de distinguir se o respondente apresenta o requisito contido no item.

$$
\mathrm{P}\left(\mathrm{U}_{\mathrm{ij}}=1 \mid \theta_{\mathrm{j}}\right)=\frac{1}{1+\mathrm{e}^{-\mathrm{a}_{\mathrm{i}}\left(\theta_{\mathrm{j}}-\mathrm{b}_{\mathrm{i}}\right)}}
$$

A Figura 1 mostra as Curvas Características de dois itens com os pares de parâmetros $\left(\mathrm{a}_{\mathrm{i}} ; \mathrm{b}_{\mathrm{i}}\right)$ iguais a $(2 ;-1)$ e $(1 ; 1)$, respectivamente. Observa-se que o item 1 é o mais discriminante (maior 'a') e o item 2 exige um valor maior do potencial empreendedor para a resposta afirmativa, dito mais difícil (maior 'b'). A escala da Figura 1 é medida em múltiplos de desvio padrão, está parametrizada na média 0 e desvio padrão 1 , escala $(0 ; 1)$, na qual o valor do potencial empreendedor pode estar entre $-\infty \mathrm{e}+\infty$. Na prática, no entanto, dificilmente os valores são inferiores a -3 ou superior a 3 .

Quando os valores dos parâmetros dos itens e/ou os valores do potencial empreendedor dos respondentes são desconhecidos, eles devem ser estimados a partir das respostas fornecidas. Os processos de estimação consistem de métodos matemáticos com algoritmos numéricos iterativos. O método da Máxima Verossimilhança Marginal inicialmente estima os parâmetros dos itens (calibra os itens), assumindo uma distribuição para o traço latente (potencial empreendedor); em seguida, o estima com os parâmetros dos itens calculados (BAKER, 2001).

$\mathrm{O}$ processo de mensurar o traço latente de indivíduos submetidos a testes parcialmente diferentes e o traço dos mesmos indivíduos submetidos a testes totalmente diferentes denomina-se equalização. A equalização consiste em colocar sobre a mesma métrica os parâmetros dos itens e o $\theta$ dos respondentes.

Cada item provê um nível de informação para um determinado valor de $\theta$, conforme a Equação 2, denominada Função de Informação do Item (EMBRETSON; REISE, 2000). Na Equação 2, $\mathrm{I}_{i}(\theta)$ é a informação provida pelo item; $\mathrm{P}_{\mathrm{i}}$ ' $(\theta)$ é a derivada de $\mathrm{P}_{\mathrm{i}}(\theta) \equiv$ Equação 1 ; e $\mathrm{Q}_{\mathrm{i}}(\theta)=1-\mathrm{P}_{\mathrm{i}}(\theta)$. Nos modelos logísticos, a informação é maior quanto maior for o valor de 'a' e quanto mais 'b' se aproxima de $\theta$.

$$
I_{i}(\theta)=\frac{\left[P_{i}^{\prime}(\theta)\right]^{2}}{P_{i}(\theta) \times Q_{i}(\theta)}
$$

A informação do teste, $\mathrm{I}(\theta)$, é o somatório de $\mathrm{I}_{i}(\theta)$.

Outra forma de expor a informação do teste é por meio do erro padrão da medida, $\operatorname{EM}(\theta)$, mostrado na Equação 3.

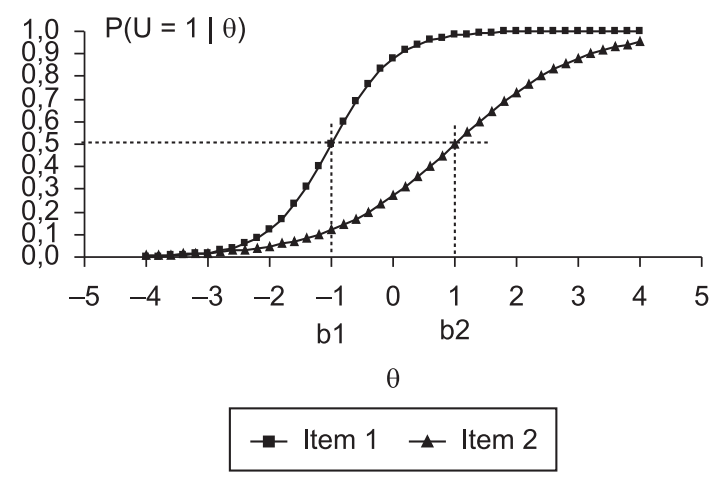

Figura 1. Curva Característica do Item (CCI). Fonte: Elaborada pelos autores. 


$$
\operatorname{EM}(\theta)=\frac{1}{\sqrt{\mathrm{I}(\theta)}}
$$

Segundo Pasquali (2003), por meio da análise das funções de informação e do erro padrão da medida é possível verificar a validade de construto do instrumento.

Em função do parâmetro dificuldade do item estar na mesma escala do traço latente do respondente, a TRI é capaz não apenas de atribuir números que permitam a comparação entre os indivíduos, mas também de fazer inferências ao traço latente deles frente a alguns itens requisitados (BEATON; ALLEN, 1992). Desta forma: (i) os itens que satisfazem simultaneamente as condições das Equações 4, 5 e 6 são denominados itens âncoras; (ii) os pontos da escala que contêm itens âncoras são os níveis âncoras; (iii) para cada nível âncora há pelo menos $65 \%$ de respondentes que 'acertam' o conjunto de itens correspondente; (iv) os respondentes deste nível acumulam os requisitos contidos nos níveis inferiores. Quando duas das três condições são atendidas, o analista pode definir itens 'quase âncoras' (ANDRADE; TAVARES; VALLE, 2000). Nas Equações 4-6, o nível $Z$ da escala é imediatamente superior ao $\mathrm{Y}$.

$$
\begin{aligned}
& P(U=1 \mid \theta=Z \geq 0,65 \\
& P(U=1 \mid \theta=Y<0,5 \\
& P(U=1 \mid \theta=Z)-\mathrm{P}(U=1 \mid \theta=\mathrm{Y}) \geq 0,3
\end{aligned}
$$

A Figura 2 ilustra o posicionamento dos respondentes $R_{k}$ em relação aos níveis âncoras -2 a 2 formados pelos itens âncoras $\mathrm{IA}_{\mathrm{w}}$.

Na Figura 2, $R_{2}$ e $R_{3}$ posicionados no nível âncora -1 possuem os requisitos questionados pelos itens $\mathrm{IA}_{1} \mathrm{IA}_{2}, \mathrm{IA}_{3}$, enquanto $\mathrm{R}_{1}$ só tem aptidão para $\mathrm{IA}_{1}$ do nível -2. $\mathrm{R}_{4}, \mathrm{R}_{5}$ e $\mathrm{R}_{6}$ são exclusivamente hábeis nos requisitos dos itens $\mathrm{IA}_{4}, \mathrm{IA}_{5}$ e IA 6 em relação aos respondentes posicionados no nível -1 e -2 .

A escala da habilidade [potencial empreendedor] é uma escala arbitrária na qual o importante são as relações de ordem existentes entre seus pontos e não necessariamente sua magnitude. (ANDRADE; TAVARES, VALLE, 2000, p 10).

Desta forma, a escala pode ser reparametrizada para média $\mu$ e desvio padrão $\sigma$ com as Equações 7-10:

$$
\begin{aligned}
& \mathrm{P}\left(\mathrm{U}_{\mathrm{ij}}=1 \mid \theta\right)=\mathrm{P}\left(\mathrm{U}_{\mathrm{ij}}=1 \mid \theta^{*}\right) \\
& \theta^{*}=(\sigma \theta)+\mu \\
& b^{*}=(\sigma b)+\mu \\
& a^{*}=\mathrm{a} / \sigma
\end{aligned}
$$

A reparametrização tem o intuito de facilitar a interpretação da escala.

\section{Procedimentos metodológicos}

Para o desenvolvimento da escala utilizaram-se dados coletados e processados por Santos (2008), o qual estruturou o modelo apresentado no Quadro 2.

No modelo de Santos (2008), o conjunto de itens para medir o potencial empreendedor foi estruturado em 3 categorias, as quais foram divididas em 12 características, gerando 120 itens, sendo 17 relacionados às categorias e 103 às características. Os itens criados foram submetidos a 664 estudantes de graduação e pós-graduação de instituições de ensino, selecionadas por acessibilidade, de Santa Catarina, Paraná, Alagoas e Pernambuco, 20\% dos quais, na ocasião, tinham negócio próprio ou participavam de algum empreendimento. Após eliminar 67 itens, Santos (2008) submeteu os 53 remanescentes para 100 empreendedores de Alagoas.

Neste trabalho, foram utilizados somente os

\begin{tabular}{|c|c|c|}
\hline $\begin{array}{l}\text { Traço } \\
\text { latente }\end{array}$ & $\begin{array}{l}\text { Categorias/ } \\
\text { itens }\end{array}$ & $\begin{array}{c}\text { Características/ } \\
\text { itens }\end{array}$ \\
\hline \multirow{12}{*}{$\begin{array}{l}\text { Potencial para } \\
\text { empreender } \\
120\end{array}$} & \multirow[t]{5}{*}{ Realização/8 } & Oportunidade/8 \\
\hline & & Persistência/8 \\
\hline & & Qualidade/9 \\
\hline & & Eficiência/10 \\
\hline & & Riscos/10 \\
\hline & \multirow[t]{4}{*}{ Planejamento } & Metas/9 \\
\hline & & Informações/8 \\
\hline & & Planejamento/8 \\
\hline & & Controle/8 \\
\hline & \multirow[t]{3}{*}{ Poder/9 } & Persuasão/9 \\
\hline & & Rede de relações $/ 8$ \\
\hline & & Autoconfiança/8 \\
\hline
\end{tabular}
103 itens provenientes das 12 características (Quadro 2) por se entender que as categorias definem as características e estas, sim, definem os itens. Os

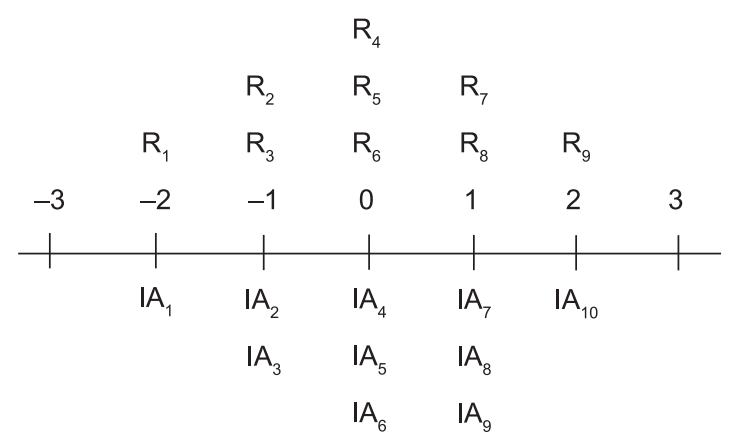

Figura 2. Escala de habilidade. Fonte: Elaborada pelos autores.

Quadro 2. Modelo teórico do potencial empreendedor.

Fonte: Adaptado de SANTOS (2008, p. 157). 
itens receberam os códigos I001 a I103. Portanto a amostra utilizada ficou composta por 764 respondentes, sendo que 664 estudantes responderam os 103 itens e 100 empreendedores responderam 53 itens.

De acordo com a definição da característica 'Riscos' (Anexo A), quanto maior o potencial empreendedor, mais se corre riscos moderados e calculados. Quatro itens (I087, I089, I093, I095), no entanto, questionam se indivíduos correm riscos baixos ou elevados. Estes itens não atendem o critério acumulativo do ML2, ou seja, não se pode dizer que quanto maior o potencial empreendedor de um indivíduo mais ousado ele é, como no item I093 'Sinto que sou ousado em relação a riscos, seja lá quais forem'. Estes itens foram descartados da análise. Portanto, foram analisados 99 itens com a TRI.

A escala utilizada por Santos (2008) foi do tipo ordinal-intervalar, contendo respostas no intervalo [0; 10]. Para utilizar o ML2 da TRI, as respostas foram dicotomizadas, ou seja, para as respostas coletadas por Santos (2008), acima de um determinado ponto foi necessário considerar que estas são afirmativas e abaixo deste ponto, negativas. Foram testados pontos de corte em valores maiores ou iguais a 7, 8 e 9, com sintaxes equivalentes no software BILOG-MG ${ }^{\circledR}$. O critério utilizado foi o de maior média para os parâmetros de discriminação do conjunto de itens. O ponto 7 obteve índice de discriminação 1,77 , enquanto 8 e 9 obtiveram 1,38 e 1,25, respectivamente. Desta forma, as respostas maiores ou iguais a $7 \mathrm{do}$ intervalo $[0 ; 10]$ equivalem ao valor binário 1 .

Com os dados dicotomizados, procedeu-se à estimação dos parâmetros dos itens, fixando-se os empreendedores como grupo de referência. Isto foi feito com o BILOG-MG ${ }^{\circledR}$. Na sequência, analisaram-se os parâmetros de discriminação dos itens (parâmetro 'a'). Baker (2001) cita que itens com 'a' $<0,65$ apresentam pouca discriminação. Neste trabalho, eliminaram-se itens com 'a' $<1,0$.

A escala original com $\mu=0$ e $\sigma=1$ foi transformada para $\mu=8$ e $\sigma=2$. Com a nova métrica, foram determinados os itens e níveis âncoras para interpretar o significado da posição de um respondente na escala.

Na TRI, é possível estabelecer a variação da informação e do erro padrão do teste em função do traço latente. Com o gráfico que contém estas informações, fez-se a análise de qual o intervalo do potencial empreendedor a escala é mais propícia.

\section{Desenvolvimento da escala}

O desenvolvimento da escala é mostrado em duas subseções. A primeira descreve a estimação dos parâmetros e analisa itens em função dos seus parâmetros. A segunda descreve a aplicação dos procedimentos de reparametrização, determinação e interpretação dos itens e níveis âncoras e a análise da informação do teste.

\subsection{Estimação dos parâmetros dos itens}

Neste trabalho, os valores do potencial empreendedor e os parâmetros dos itens foram estimados. Utilizou-se o Método de Máxima Verossimilhança Marginal. Observou-se que houve convergência dos algoritmos numéricos de estimação.

No primeiro processo de estimação, 15 itens obtiveram o parâmetro de discriminação 'a' menor que 1 e foram descartados e o item I019 foi descarado por apresentar erro padrão do parâmetro 'b' alto, 0,54. Foi então executada uma segunda estimação com os 83 itens remanescentes que compõem o instrumento. Os 103 itens com seus parâmetros estimados são mostrados no Apêndice A.

A seguir são sintetizados os conteúdos dos itens que têm valores extremos dos parâmetros ' $a$ ' e ' $b$ '.

Os 10 itens mais discriminativos, com 'a' entre 2,60 e 3,41, questionam o apreço por encarar desafios, a crença na capacidade de resolver problemas, alcançar objetivos e liderar pessoas, saber estabelecer metas e os passos para alcançá-las. São eles: I002, I035, I036, I039, I041, I042, I057, I059, I066 e I072. Os 10 menos discriminativos, com 'a' entre 1,03 e 1,25, questionam se os indivíduos percebem que decisões erradas, falta de planejamento e de controle podem levá-los ao fracasso; se creem que clientes exigem qualidade e bom atendimento, que podem quantificar metas, que os planejamentos podem ser flexíveis e a eficiência é uma fonte de benefícios; se são exigentes para com a qualidade do que fazem e se acham que é necessário ter uma rede de relacionamentos. Estes itens são: I006, I016, I018, I025, I032, I038, I040, I054, I076 e I085 (Apêndice A).

Os 10 itens da escala com maior parâmetro de dificuldade, ' $b$ ' entre $-0,93$ e $-0,06$, questionam se os indivíduos são proativos, correm riscos, são bastante persuasivos, consideram-se autônomos, definem objetivos e detalham os passos para alcançá-los, mantêm registros de suas ações, acreditam que podem quantificar suas metas e na flexibilidade do planejamento. Os itens são: I008, I012, I038, I045, I060, I061, I071, I072, I076, I086 (Apêndice A). Os 10 itens mais 'fáceis', 'b' entre $-2,03$ e -2,62, questionam se os indivíduos entendem obstáculo como algo a ser superado, gostam de fazer as coisas bem feitas, acreditam que obtêm benefícios com a eficiência dos processos, que é importante estabelecer prazos, custos e responsáveis e que é necessário ofertar produtos e serviços com qualidade, se aprendem com os próprios erros, procuram estar atualizados, buscam informações de especialistas quando necessário e procuram ajudar sua rede de relações. Os itens são: I025, I033, I034, I054, I055, I073, I074, I077, I085, I103 (Apêndice A).

\subsection{Interpretação da escala}

O primeiro procedimento para interpretação foi a mudança da escala com métrica $\mu=0$ e $\sigma=1$ para 
Tabela 1. Análise da identificação de itens âncoras.

\begin{tabular}{|c|c|c|c|c|c|c|c|c|c|c|c|c|c|c|}
\hline \multirow[t]{2}{*}{ Item } & \multicolumn{2}{|c|}{ Parâmetros } & \multirow[t]{2}{*}{$\theta^{*}$} & \multirow[t]{2}{*}{4} & \multirow[t]{2}{*}{5} & \multirow[t]{2}{*}{6} & \multirow[t]{2}{*}{7} & \multirow[t]{2}{*}{8} & \multirow[t]{2}{*}{9} & \multirow[t]{2}{*}{10} & \multirow{2}{*}{$\begin{array}{l}\mathbf{P}(\mathbf{Z})- \\
\mathbf{P}(\mathbf{Y})\end{array}$} & \multicolumn{3}{|c|}{ Atende a equação? } \\
\hline & $\mathbf{a}^{*}$ & $\mathbf{b}^{*}$ & & & & & & & & & & 4 & 5 & 6 \\
\hline I036 & 1,71 & 5,60 & $\mathbf{P}\left(\mathbf{U}=\mathbf{1} \mid \theta^{*}\right)$ & 0,06 & 0,26 & 0,66 & 0,92 & 0,99 & 1,00 & 1,00 & 0,40 & Sim & Sim & Sim \\
\hline I037 & 1,18 & 6,09 & & 0,08 & 0,22 & 0,47 & 0,75 & 0,91 & 0,97 & 0,99 & 0,27 & Sim & Sim & Não \\
\hline I040 & 0,68 & 5,72 & & 0,24 & 0,38 & 0,55 & 0,70 & 0,82 & 0,90 & 0,95 & 0,16 & Sim & Não & Não \\
\hline
\end{tabular}

Fonte: Elaborada pelos autores.

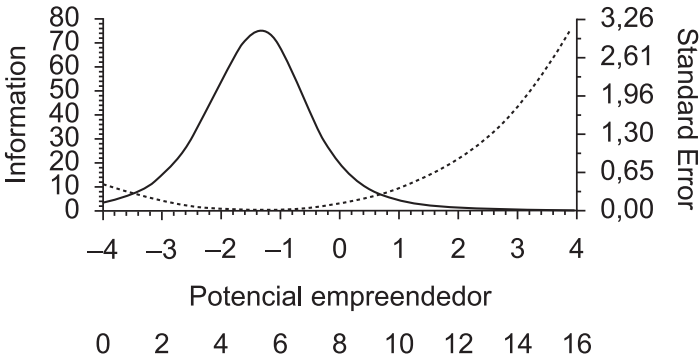

Figura 3. Curva de informação do teste. Fonte: Elaborada pelos autores.

$\mu=8$ e $\sigma=2$ com as Equações 7-10 tendo como objetivo trabalhar com números naturais no intervalo em que prevalece a informação do teste.

O segundo procedimento foi a determinação dos itens e níveis âncoras. Este foi realizado aplicando a Equação 1 com os parâmetros já estimados sobre os valores da escala reparametrizada variando em intervalos de 1,0 desvio padrão obtendo $\mathrm{P}\left(\mathrm{U}=1 \mid \theta^{*}\right)$ e verificando se cada item atende às condições das Equações 4-6 com tolerância de $\mathrm{P}\left(\mathrm{U}=1 / \theta^{*}\right)$ de 0,03 . A Tabela 1 exemplifica a análise de 3 itens:

Na Tabela 1, vê-se que os itens I036, I037 e I040 atendem respectivamente a 3, 2 e 1 condições das Equações 4-6. Sendo assim, o primeiro item é âncora para o nível 6, o segundo, quase âncora para o nível 7 e o terceiro item é um item 'comum'. Com este procedimento, a escala apresentou 42 itens âncoras e quase âncoras posicionados em 6 níveis âncoras: 4, 5 , 6, 7, 8 e 9 (Apêndice B). No entanto, os níveis âncoras 4, 8 e 9 possuem 2, 1 e 1 itens respectivamente, o que não permite que sejam bem interpretados.

A seguir estão descritas as características do potencial empreendedor dos indivíduos em relação ao nível em que se encontram na escala, segundo a interpretação dos autores.

As pessoas posicionadas no nível 5 ou superiores da escala gostam de realizar seu trabalho de forma assídua e correta. Procuram obter aprendizado sobre os assuntos pertinentes ao ramo em que atuam e saber a amplitude dos riscos para tomar decisões. Entendem que obstáculos existem para ser superados e não se abatem com os erros cometidos, buscando de forma permanente atingir seus objetivos. Procuram prestar suporte à sua rede de relações.
Os indivíduos com potencial empreendedor maior ou igual a 6 , além das características dos níveis anteriores, têm expectativas altas para consigo. São hábeis em identificar oportunidades, enxergar as necessidades das pessoas e encontrar meios para atendê-las. Buscam informações para enfrentar desafios e obter vantagens competitivas. Sabem o que querem alcançar e, para isso, fazem planejamentos com os quais monitoram e alteram suas atividades para obterem êxito. Têm boa habilidade de relacionamento interpessoal: procuram manter contato constante com sua rede de relações, são motivadores, líderes e administradores de conflitos.

Aqueles que se encontram no nível maior ou igual a 7 da escala consideram-se independentes para tomar decisões sobre a sua vida e correr riscos calculados. São proativos e capazes de filtrar as oportunidades que são lucrativas. Têm objetivos claramente definidos e são bastante habilidosos em detalhar metas e os passos para alcançá-las. Sabem maneiras de convencer as pessoas a mudarem de opinião e não só mantêm uma rede de relacionamentos, mas a utilizam para alcançar seus objetivos.

Por fim, observa-se na Figura 3 que a escala é mais adequada para medir o potencial empreendedor daqueles que se encontram no intervalo $[2 ; 8]$, pois há bom nível de informação e erro padrão baixo, com ápice em torno do ponto 5,5. À medida que o potencial empreendedor se distancia deste intervalo, perde-se confiabilidade da medida. Por meio da interpretação dos níveis âncoras, verificou-se que indivíduos posicionados no nível 7 (ou superior) apresentam características relevantes para conduzir atividades empreendedoras. Este nível está pouco abaixo da média da amostra dos empreendedores. Assim, conclui-se que os empreendedores, em média, possuem bom potencial empreendedor e que a escala, que tem boa informação e erro baixo do nível 2 ao 8 , é adequada para avaliar indivíduos com baixo até moderadamente alto potencial empreendedor.

\section{Conclusões e recomendações}

Inicialmente, observou-se que, entre as variáveis sensíveis ao empreendedorismo, destaca-se o próprio empreendedor. Sob premissas de que este tem características e traços de personalidade singulares e propícios ao empreendedorismo em 
relação à população, escolheu-se trabalhar com esta linha de pesquisa. Estas foram consideradas pertencentes à dimensão que se propôs medir: o potencial empreendedor. Para o desenvolvimento da escala, utilizou-se a abordagem da Teoria da Resposta ao Item com o modelo logístico de 2 parâmetros.

Um dos pontos positivos verificados com a utilização da TRI foi o de poder utilizar respostas coletadas de instrumentos diferentes, porém com alguns itens comuns: as 664 repostas dos estudantes aos 103 itens e as 100 respostas dos empreendedores aos 53 itens. A escala pôde ser fixada considerando um grupo de referência, significando que o centro da escala é o potencial empreendedor médio da amostra de empreendedores.

A escala do potencial empreendedor ficou composta por 83 itens. A fim de interpretá-la, calcularam-se os níveis e itens âncoras. Foram identificados 42 itens âncoras e quase âncoras, posicionados em 6 níveis, dos quais, 3 foram interpretados. A possibilidade de interpretação da escala, isto é, entender o que significa um indivíduo estar posicionado em determinado nível, em termos das características identificadas pelos itens, talvez tenha sido a maior vantagem da aplicação da TRI.

Outra análise importante advinda da curva de informação e do erro do teste, a qual indica a região da escala que produz estimativas mais precisas, em conjunto com a interpretação dos níveis âncoras, mostrou que a escala é mais adequada para avaliar indivíduos no intervalo de baixo a moderadamente alto potencial empreendedor. Sugere-se criar e calibrar itens com parâmetros de dificuldade mais elevados para interpretar e avaliar com boa precisão níveis mais elevados. Ressalta-se que, uma vez criado e aplicado o novo instrumento, é possível aproveitar as informações contidas na atual amostra, por meio do processo de equalização da TRI.

\section{Referências}

ACS, Z. J. How is entrepreneurship good for economic grouth? In: ECONOMIC CONFERENCE OF PROGRESS FOUNDATION, 25., 2007, Great Barrington, Massachusetts. Proceedings... 2007. p. 1-21. Disponível em:<http://www.progressfoundation.ch/ referate.asp>. Acesso em: 29 jun. 2011.

ACS, Z. J.; DESAI, S.; HESSELS, J. Entrepreneurship, economic development and institutions. Small Business Economy, v. 31, p. 219-234, 2008. http://dx.doi. org/10.1007/s11187-008-9135-9

AJZEN, I.The theory of planned behavior. Organizational Behavior and Human Decision Processes, v. 50, 1991, p. 179-211. http://dx.doi. org/10.1016/0749-5978(91)90020-T

ANDRADE, D. F.; TAVARES, H. R.; VALLE, R. C. Teoria da Resposta ao Item: conceitos e aplicações. Associação Brasileira de Estatística, 2000.
ANDREOLA, W. B. Psicometria moderna: características e tendências. Estudos em Avaliação Educacional, v. 20, n. 43, p. 319-340, 2009.

ASLETE, J. W. Aspects of entrepreneurial success. Journal of Small Business and Enterprise Development, v. 15, n. 3, p. 584-594, 2008. http:// dx.doi.org/10.1108/14626000810892364

BAKER, F. B. The basicsof item response theory. 2 th ed. ERIC Clearinghouseon Assessment and Evaluation, 2001.

BANDURA, A. Self-efficacy in changing societies Cambridge: Cambridge University Press, 1997.

BEATON, A. E.; ALLEN, N. L. Interpreting Scales Thought Scale Anchoring. Journal of Education Statistics, v. 17, n.2, p. 191-204, 1992. http://dx.doi.org/10.2307/1165169

BRASDSTÄTTER, H. Becoming na entrepreneur- a question of personality structure? Journal of Economic Psychology, v. 18, p. 157-177, 1997. http://dx.doi. org/10.1016/S0167-4870(97)00003-2

BROKHAUS, R. H. Risk taking propensity of entrepreneurs. Academy of Management Journal, v. 23, n. 3, p.509520, 1980. http://dx.doi.org/10.2307/255515

CAI, L.; YIN, M.; ZHANG, Y. Empirical study on the effects of entrepreneurial traits on entrepreneuria lorientation. In: INTERNATIONAL CONFERENCE ON MANAGEMENT SCIENCE \& ENGINEERING, 15., 2008, Long Beach. Proceedings... Long Beach, 2008. p. 1386-1391.

CHEN, C. C.; GREENE, P. C.; CRICK, A. Does entrepreneurial self-efficacy distinguish entrepreneurs from managers? Journal of Business Venturing, v.13, p. 295-316,1998. http://dx.doi.org/10.1016/ S0883-9026(97)00029-3

CORNELIUS, B.; LANDSTRÖM, H.; PERSSON, O. Entrepreneurial studies: the dynamic research front of a developing social science. Entrepreneur ship Theory and Practice, p. 375-398, 2006. http://dx.doi. org/10.1111/j.1540-6520.2006.00125.x

EMBRETSON, S.; REISE, S. P. Item Response Theory for Psychologists. New Jersey: Lawrence Erlbaum Associates, Inc. Publishers, 2000.

FAYOLLE, A.; GAILLY, B. Using theory of planner behavior to assessent repreneurship teaching programs: a first experimentation. In: ANNUAL INTENT CONFERENCE, 14., 2004, Napoli. Proceedings... 2004. 12p.

FILION, L. J. O empreendedorismo como tema de estudos superiores: Empreendedorismo, Ciência, Técnica e Arte. Brasília: CNI. IEL Nacional, 2000.

HANSEMARK, O. C. The effects of na entrepreneurial program of need of achievementand lócus of control of reinforcement. International Joural of Entrepreneurial Behavior \& Research, v. 4, n. 1, p. 28-50, 1998. http:// dx.doi.org/10.1108/13552559810203957

HMIELESC, K. M.; CORBETT, A. C. The contrasting interaction effects of improvisational behavior with entrepreneurial self-efficacyon new venture performance and entrepreneur work satisfaction. Journal of Business Venturing, v. 23, p. 482-496, 2008. http://dx.doi. org/10.1016/j.jbusvent.2007.04.002 
INÁCIO JÚNIOR, E.; GIMENEZ, F. A. P. Potencial empreendedor: um instrumento para mensuração. Revista de Negócios, v. 9, n. 2, p. 107-116, 2004.

LEZANA, A. G. R.; TONELLI, A. O comportamento do empreendedor. In: MORI, F. (Org.). Empreender: identificando, avaliando e planejando um novo negócio. Florianópolis: Escola de Novos Empreendedores, 2004. p. 13-66.

LITTUNEM, H. Entrepreneurship and the characteristics of the entrepreneurial personality. International Journal of Behavior \& Research, v. 6, n.6, p. 295-309,2000.

LOPES JUNIOR, G. S.; SOUSA E. C. L. Atitude empreendedora em proprietários-gerentes de pequenas empresas: construção de um instrumento de medida. REAd, ed. 48, v. 11, n. 6, 2005.

MARKMAN, G. D.; BARON, R. A. Personentrepreneurshipfit: why some people are more successful as entrepreneurs than others. Human Resource Management Review, v. 13, p. 281-301, 2003.

MASLOW, A. H. Maslow no gerenciamento. Rio de Janeiro: Qualymark, 2001. p. 265-270

MURPHY, P. J.; LIAO, J.; WELSCH, H. P. A conceptual history of entrepreneurial thought. Journal of Management History, v. 2, n. 1, p. 12-35, 2006. http:// dx.doi.org/10.1108/13552520610638256

McCLELLAND, D. C. La sociedad ambiciosa: factores psicológicos em desarrollo economico. Madrid: Ediciones Guadarrama, 1968.

McCLELLAND,D. C. et al. The identification and assessment of competencies and other personal characteristics of entrepreneurs in developing countries: Report. Boston: McBerand Company, 1987. 402 p.

MINER, J. B. Evidence for the existence of a set of personality types, defined by psychological tests that predict entrepreneurial success. Wellesley: Frontiers of Entrepreneurship Research, Babson College, 1996. Disponível em: <http://www.babson.edu/ entrep/fer/ papers96/miner/>. Acesso em: 28 set. 2009.
MORALES, S. A. Relação entre competências e tipos psicológicos junguianos nos empreendedores. 2004. 199 f. Tese (Doutorado em Engenharia de Produção)-Universidade Federal de Santa Catarina, Florianópolis, 2004.

PASQUALI, L. Psicometria: teoria dos testes na psicologia e na educação. Petrópolis: Vozes, 2003.

PASQUALI, L.; PRIMI, R. Fundamentos da teoria da resposta ao item. Avaliação Psicológica, v. 2, n. 2, p. 99-110,2003.

PANDEY, J.; TEWARY, N. B. Locus of control and achievement values of entrepreneurs. Journal of Occupational Psychology, v. 52, p. 107-111, 1979. http://dx.doi.org/10.1111/j.2044-8325.1979.tb00446.x

ROTTER, J. B.; HOCHREICH, D. J. Personalidade. Tradução de Maria G. C. Maron. Rio de Janeiro: Interamericana, 1980.

SANTOS, P. C. F. Uma escala para identificar potencial empreendedor. 2008. 364f. Tese (Doutorado em Engenharia de Produção)-Universidade Federal de Santa Catarina, Florianópolis, 2008.

SHANE, C.; LOCKE, E.A.; COLLINS, C. J. Entrepreneurial motivation. Human Resource Management Review, v. 13, p. 257-279, 2003. http://dx.doi.org/10.1016/ S1053-4822(03)00017-2

UNITED NATIONS CONFERENCE ON TRADE AND DEVELOPMENT-UNCTAD. Entrepreneurship and economic development: theEmpretec show case. 2005. Disponível em:<http://www.unctad.org/en/docs/ webiteteb20043_en.pdf>. Acesso em: 10 jul. 2011.

Van Der LINDEN, W. J.; HAMBLETON, R. K. Hand book of modern item response theory. New York: Spring-Verlag, 1997.

Van EMMERIK, H. et al.Associations of culture and personality with McClelland's motives: a crosscultural study of managers in 24 countries. Group \& Organization Management, v. 35, n. 3, p. 329-367, 2010. http://dx.doi.org/10.1177/1059601110370782 
Anexo A. Conceitualização das características do potencial empreendedor. Fonte: Santos (2008, p. 231).

\begin{tabular}{|c|c|}
\hline Característica & Descrição \\
\hline Autoconfiança & $\begin{array}{l}\text { Busca de maior autonomia em relação aos controles que possam existir em sua vida. Crença } \\
\text { em si próprio e independência de pensamento. Confiante no que faz ou pode fazer. }\end{array}$ \\
\hline Controle & $\begin{array}{l}\text { Capacidade de acompanhar a execução dos planos elaborados, manter registros e utilizá-los } \\
\text { no processo decisório, checar o alcance dos resultados obtidos, e de realizar mudanças e } \\
\text { adaptações sempre que necessário. }\end{array}$ \\
\hline Eficiência & $\begin{array}{l}\text { Capacidade de fazer as coisas de maneira correta e, caso seja necessário, promover } \\
\text { rapidamente mudanças para se adaptar as alterações ocorridas no ambiente. Capacidade de } \\
\text { encontrar e conseguir operacionalizar formas de fazer as coisas melhor, mais rápidas e mais } \\
\text { baratas. Capacidade de desenvolver ou utilizar procedimentos para assegurar que o trabalho } \\
\text { seja terminado a tempo. }\end{array}$ \\
\hline Informações & $\begin{array}{l}\text { Disponibilidade para aprender e demonstrar sede de conhecimentos. Interesse em encontrar } \\
\text { novas informações em sua área de atuação ou mesmo fora dela. Estar atento a todos } \\
\text { os fatores, internos e externos, relacionados à sua organização/empresa. Interesse em } \\
\text { saber como fabricar produtos ou fornecer serviços. Disponibilidade para buscar ajuda de } \\
\text { especialistas em assuntos técnicos ou comerciais. }\end{array}$ \\
\hline Metas & $\begin{array}{c}\text { Capacidade de mostrar determinação, senso de direção e de estabelecer objetivos e metas } \\
\text { definindo de forma clara aonde pretende chegar. Capacidade de definir rumos e objetivos } \\
\text { mensuráveis. }\end{array}$ \\
\hline Oportunidade & $\begin{array}{l}\text { Mostrar que dispõe de senso de oportunidade, ou seja, está atento ao que acontece à sua } \\
\text { volta e a partir daí, ao identificar as necessidades das pessoas ou do mercado, ser capaz de } \\
\text { aproveitar situações incomuns para iniciar novas atividades ou negócios. }\end{array}$ \\
\hline Persistência & $\begin{array}{l}\text { Capacidade de manter-se firme na busca do sucesso, demonstrando persistência para } \\
\text { alcançar seus objetivos e metas, superando obstáculos pelo caminho. Capacidade de } \\
\text { distinguir teimosia de persistência, admitir erros e saber redefinir metas e estratégias. }\end{array}$ \\
\hline Persuasão & $\begin{array}{l}\text { Habilidade para influenciar pessoas quanto à execução de tarefas ou de ações que viabilizem } \\
\text { o alcance de seu objetivo. Capacidade de convencer e motivar pessoas, liderar equipes e } \\
\text { estimulá-las usando as palavras e ações adequadas para influenciar e persuadir. }\end{array}$ \\
\hline Planejamento & $\begin{array}{l}\text { Disponibilidade para planejar suas atividades definindo objetivos. Capacidade de planejar } \\
\text { detalhando tarefas. Ser capaz de atuar com o planejamento, a execução e o controle. } \\
\text { Acreditar na importância do planejamento. }\end{array}$ \\
\hline Qualidade & $\begin{array}{c}\text { Crença de que produtos ou serviços com qualidade possuem maior competitividade. } \\
\text { Capacidade de cumprir prazos. Possuir altos padrões de exigência quanto ao requisito } \\
\text { qualidade. Atua sempre procurando alcançar ou superar os padrões de qualidade } \\
\text { estabelecidos. }\end{array}$ \\
\hline Rede de relações & $\begin{array}{c}\text { Capacidade de criar rede de relações e de pôr-se em contato com pessoas-chaves que possam } \\
\text { auxiliar no alcance de seus objetivos. Capacidade de atuar desenvolvendo e mantendo redes } \\
\text { de relações comerciais ou não. }\end{array}$ \\
\hline Riscos & $\begin{array}{c}\text { Ousadia para enfrentar situações de risco controlado. Capacidade de estabelecer limites para } \\
\text { situações de risco. }\end{array}$ \\
\hline
\end{tabular}


Apêndice A. Itens da escala do potencial empreendedor com o ML2 da TRI. a: parâmetro de discriminação, b: parâmetro de dificuldade, Ea: erro do parâmetro de discriminação, Eb: erro do parâmetro de dificuldade, a*: parâmetro de discriminação reparametrizado, $b^{*}$ : parâmetro de dificuldade reparametrizado. Nota: Itens eliminados: (1) não atende ao critério cumulativo do modelo, (2) baixa discriminação, (3) erro padrão elevado. Os valores de (2) e (3) são provenientes do $1^{\circ}$ processo de estimação.

\begin{tabular}{|c|c|c|c|c|c|c|c|}
\hline Código & $\mathbf{a}$ & Ea & b & $\mathbf{E b}$ & $a^{*}$ & $\mathbf{b}^{*}$ & Descrição \\
\hline I001 & 1,43 & 0,15 & $-1,03$ & 0,07 & 0,72 & 5,94 & Sou eu quem controla a minha vida. \\
\hline I002 & 3,22 & 0,37 & $-1,64$ & 0,08 & 1,61 & 4,72 & $\begin{array}{l}\text { Acredito na minha capacidade de resolver as coisas que me } \\
\text { desafiam. }\end{array}$ \\
\hline I003 & 1,48 & 0,21 & $-1,76$ & 0,16 & 0,74 & 4,48 & $\begin{array}{l}\text { Aceito normas como guias de conduta, em vez de correntes para } \\
\text { me prenderem. }\end{array}$ \\
\hline I004 & 2,46 & 0,23 & $-1,15$ & 0,05 & 1,23 & 5,70 & $\begin{array}{l}\text { Tenho autoconfiança e dependo de mim para decidir os rumos de } \\
\text { minha vida. }\end{array}$ \\
\hline $\mathrm{I} 005$ & 1,04 & 0,13 & $-1,15$ & 0,11 & 0,52 & 5,69 & $\begin{array}{l}\text { Aceito orientações de outrem apenas como sugestões, pois, cabe } \\
\text { me decidí-las ou não. }\end{array}$ \\
\hline I006 & 1,03 & 0,13 & $-1,29$ & 0,12 & 0,51 & 5,41 & $\begin{array}{l}\text { Em grande parte os meus fracassos decorreram de falhas } \\
\text { provocadas por decisões erradas que tomei. }\end{array}$ \\
\hline $\mathrm{I} 007^{(2)}$ & 0,73 & 0,14 & $-1,91$ & 0,28 & & & Ninguém nasce para ser um perdedor. \\
\hline I008 & 2,07 & 0,20 & $-0,93$ & 0,05 & 1,03 & 6,13 & $\begin{array}{l}\text { Considero-me autônomo e capaz de enxergar quais os melhores } \\
\text { rumos para a minha vida. }\end{array}$ \\
\hline I009 & 2,54 & 0,32 & $-1,69$ & 0,11 & 1,27 & 4,62 & Vejo o planejamento como um guia para controlar as minhas ações. \\
\hline I010 & 1,79 & 0,22 & $-1,45$ & 0,10 & 0,89 & 5,10 & Costumo verificar se as coisas estão acontecendo como planejei. \\
\hline I011 & 1,64 & 0,19 & $-1,09$ & 0,07 & 0,82 & 5,81 & $\begin{array}{l}\text { Quando eu verifico que os resultados diferem do estabelecido eu } \\
\text { altero meu planejamento. }\end{array}$ \\
\hline $\mathrm{I} 012$ & 1,49 & 0,16 & $-0,52$ & 0,06 & 0,74 & 6,95 & Costumo fazer anotações e manter registros das minhas ações. \\
\hline I013 & 1,97 & 0,20 & $-1,06$ & 0,06 & 0,99 & 5,88 & Consulto meus registros antes de tomar decisões. \\
\hline I014 & 2,17 & 0,23 & $-1,17$ & 0,06 & 1,09 & 5,66 & Meus controles me auxiliam na revisão de meus planos. \\
\hline $\mathrm{I} 015^{(2)}$ & 0,90 & 0,15 & $-1,69$ & 0,21 & & & Sou completamente descontrolado, portanto não anoto nada. \\
\hline I016 & 1,12 & 0,17 & $-1,58$ & 0,16 & 0,56 & 4,84 & $\begin{array}{l}\text { Acredito que as pessoas que não exercem algum tipo de controle } \\
\text { sobre suas vidas tendem ao fracasso. }\end{array}$ \\
\hline I017 & 2,08 & 0,25 & $-1,73$ & 0,12 & 1,04 & 4,55 & Gosto de cumprir prazos. \\
\hline I018 & 1,25 & 0,19 & $-1,75$ & 0,18 & 0,63 & 4,50 & $\begin{array}{l}\text { A todo o tempo eu exijo que as coisas sejam feitas da maneira } \\
\text { correta. }\end{array}$ \\
\hline $\mathrm{I} 019^{(3)}$ & 1,11 & 0,25 & $-3,08$ & 0,54 & & & $\begin{array}{l}\text { Estou convicto de que o cliente merece ser atendido com } \\
\text { presteza. }\end{array}$ \\
\hline $\mathrm{I} 020^{(2)}$ & 0,76 & 0,15 & $-2,09$ & 0,31 & & & $\begin{array}{l}\text { Quando o cliente pede que seja feito de determinada forma é } \\
\text { necessário que ele seja atendido. }\end{array}$ \\
\hline I021 & 2,21 & 0,28 & $-1,85$ & 0,13 & 1,10 & 4,30 & $\begin{array}{l}\text { Gosto de realizar meus trabalhos de forma correta e dentro dos } \\
\text { prazos estabelecidos. }\end{array}$ \\
\hline I022 & 1,41 & 0,16 & $-1,23$ & 0,09 & 0,71 & 5,55 & $\begin{array}{l}\text { Não preciso que ninguém me cobre para que eu faça as coisas de } \\
\text { forma correta. }\end{array}$ \\
\hline I023 & 1,87 & 0,24 & $-1,61$ & 0,12 & 0,93 & 4,77 & $\begin{array}{l}\text { Se for necessário fazer algo eu faço, antes que alguém me diga } \\
\text { que devo fazê-lo. }\end{array}$ \\
\hline I024 & 2,38 & 0,28 & $-1,69$ & 0,10 & 1,19 & 4,63 & $\begin{array}{l}\text { Quando é preciso eu faço as adaptações necessárias para que as } \\
\text { coisas funcionem. }\end{array}$ \\
\hline I025 & 1,25 & 0,20 & $-2,36$ & 0,27 & 0,62 & 3,29 & $\begin{array}{l}\text { Se eu fizer mais rápido, de forma melhor e com menor custo eu } \\
\text { saio ganhando. }\end{array}$ \\
\hline I026 & 2,11 & 0,23 & $-1,56$ & 0,10 & 1,05 & 4,88 & Quando é preciso mudar tudo, para ter melhor resultado, eu mudo. \\
\hline I027 & 2,30 & 0,26 & $-1,61$ & 0,10 & 1,15 & 4,78 & Busco constantemente novos conhecimentos. \\
\hline $\mathrm{I} 028$ & 2,45 & 0,27 & $-1,62$ & 0,09 & 1,23 & 4,76 & Procuro estar informado sobre as coisas pertinentes ao que faço. \\
\hline I029 & 2,09 & 0,23 & $-1,51$ & 0,09 & 1,05 & 4,97 & Tenho ânsia de aprender para poder enfrentar novos desafios. \\
\hline $\mathrm{I} 030$ & 2,55 & 0,33 & $-1,89$ & 0,13 & 1,28 & 4,23 & $\begin{array}{l}\text { Quando estou em determinado ramo eu tenho que aprender tudo } \\
\text { sobre ele. }\end{array}$ \\
\hline I031 & 2,26 & 0,24 & $-1,50$ & 0,09 & 1,13 & 4,99 & Quero saber cada vez mais, pois só assim eu saio na dianteira. \\
\hline I032 & 1,37 & 0,17 & $-1,10$ & 0,09 & 0,68 & 5,79 & $\begin{array}{l}\text { Acredito que estudando o que os outros fazem eu posso fazer } \\
\text { melhor e mais barato. }\end{array}$ \\
\hline
\end{tabular}


Apêndice A. Continuação..

\begin{tabular}{|c|c|c|c|c|c|c|c|}
\hline Código & $\mathbf{a}$ & Ea & b & $\mathbf{E b}$ & $\mathbf{a}^{*}$ & $\mathbf{b}^{*}$ & Descrição \\
\hline I033 & 2,15 & 0,32 & $-2,20$ & 0,19 & 1,07 & 3,59 & $\begin{array}{l}\text { O mundo é dinâmico e eu preciso acompanhá-lo buscando } \\
\text { sempre novos conhecimentos. }\end{array}$ \\
\hline I034 & 2,41 & 0,37 & $-2,18$ & 0,18 & 1,20 & 3,65 & $\begin{array}{l}\text { Se for preciso pedirei ajuda a especialistas que me ensinem como } \\
\text { fazer as coisas da melhor forma. }\end{array}$ \\
\hline $\mathrm{I} 035$ & 2,78 & 0,25 & $-1,10$ & 0,05 & 1,39 & 5,79 & Gosto de estabelecer objetivos e metas para me sentir desafiado. \\
\hline I036 & 3,41 & 0,31 & $-1,20$ & 0,05 & 1,71 & 5,60 & Sei onde pretendo chegar e o quanto pretendo alcançar. \\
\hline I037 & 2,36 & 0,21 & $-0,95$ & 0,05 & 1,18 & 6,09 & O que eu pretendo alcançar está claramente definido. \\
\hline I038 & 1,13 & 0,15 & $-0,51$ & 0,07 & 0,56 & 6,97 & Em minha opinião metas são coisas que posso quantificar. \\
\hline I039 & 3,05 & 0,26 & $-1,03$ & 0,04 & 1,52 & 5,93 & Eu sei determinar claramente quais são meus objetivos e metas. \\
\hline I040 & 1,35 & 0,17 & $-1,14$ & 0,09 & 0,68 & 5,72 & Objetivos e metas são coisas muito vagas para mim. \\
\hline I041 & 2,88 & 0,25 & $-0,98$ & 0,04 & 1,44 & 6,03 & $\begin{array}{l}\text { Sou capaz de traçar um rumo e estabelecer os ganhos que vou ter } \\
\text { no final. }\end{array}$ \\
\hline I042 & 3,04 & 0,26 & $-1,00$ & 0,04 & 1,52 & 6,00 & Sei que posso definir meus rumos de curto, médio e longo prazos. \\
\hline I043 & 2,50 & 0,27 & $-1,54$ & 0,08 & 1,25 & 4,92 & Tenho convicção que vou alcançar meus objetivos e metas. \\
\hline I044 & 1,48 & 0,18 & $-1,53$ & 0,12 & 0,74 & 4,94 & $\begin{array}{l}\text { Vivo em estado de alerta para alguma oportunidade que me possa } \\
\text { surgir. }\end{array}$ \\
\hline I045 & 1,47 & 0,16 & $-0,56$ & 0,06 & 0,73 & 6,88 & Eu procuro fazer as coisas antes dos outros para sair na frente. \\
\hline I046 & 2,21 & 0,24 & $-1,54$ & 0,09 & 1,10 & 4,91 & $\begin{array}{l}\text { Creio sinceramente que as oportunidades estão aí para serem } \\
\text { identificadas. }\end{array}$ \\
\hline $\mathrm{I} 047^{(2)}$ & 0,73 & 0,13 & $-0,67$ & 0,11 & & & $\begin{array}{l}\text { Fazer o que os outros estão fazendo não ajuda a sobrevivência de } \\
\text { um negócio. }\end{array}$ \\
\hline I048 & 1,73 & 0,19 & $-1,34$ & 0,09 & 0,86 & 5,33 & Gosto de me informar sobre as necessidades das pessoas. \\
\hline I049 & 1,63 & 0,19 & $-1,23$ & 0,09 & 0,82 & 5,53 & Sou sensível às novidades que são fonte de novas oportunidades. \\
\hline I050 & 1,68 & 0,18 & $-1,39$ & 0,09 & 0,84 & 5,22 & $\begin{array}{l}\text { Percebo as necessidades dos outros e como elas podem ser } \\
\text { satisfeitas. }\end{array}$ \\
\hline I051 & 2,12 & 0,19 & $-0,98$ & 0,05 & 1,06 & 6,03 & $\begin{array}{l}\text { Sinto me capaz de identificar oportunidades de negócios e sair } \\
\text { lucrando com isso. }\end{array}$ \\
\hline I052 & 1,44 & 0,16 & $-1,30$ & 0,10 & 0,72 & 5,39 & Não me deixo abater pelo fracasso. \\
\hline $\mathrm{I} 053$ & 2,12 & 0,26 & $-1,81$ & 0,13 & 1,06 & 4,37 & Quando levo um tombo levanto e continuo. \\
\hline I054 & 1,28 & 0,19 & $-2,14$ & 0,22 & 0,64 & 3,72 & $\begin{array}{l}\text { Encaro o fracasso como fonte de aprendizado para não cometer o } \\
\text { mesmo erro novamente. }\end{array}$ \\
\hline I055 & 2,14 & 0,29 & $-2,03$ & 0,16 & 1,07 & 3,94 & Entendo que os obstáculos existem para serem superados. \\
\hline I056 & 1,87 & 0,22 & $-1,61$ & 0,11 & 0,94 & 4,77 & $\begin{array}{l}\text { Não confundo persistência com teimosia e só persisto se vejo } \\
\text { chances de sucesso. }\end{array}$ \\
\hline I057 & 2,63 & 0,31 & $-1,75$ & 0,10 & 1,31 & 4,51 & Busco, de forma permanente, atingir meus objetivos. \\
\hline I058 & 2,43 & 0,25 & $-1,46$ & 0,08 & 1,22 & 5,07 & $\begin{array}{l}\text { Quando cometo um erro de planejamento, redefino as coisas e } \\
\text { vou em frente. }\end{array}$ \\
\hline I059 & 3,02 & 0,27 & $-1,17$ & 0,05 & 1,51 & 5,67 & $\begin{array}{l}\text { Tenho um rumo traçado e procuro segui-lo, mesmo quando } \\
\text { enfrento dificuldades. }\end{array}$ \\
\hline I060 & 1,47 & 0,14 & $-0,06$ & 0,06 & 0,73 & 7,89 & Orgulho-me de persuadir as pessoas a fazerem o que eu quero. \\
\hline I061 & 2,14 & 0,20 & $-0,81$ & 0,05 & 1,07 & 6,39 & Tenho formas de convencer as pessoas a mudarem de opinião. \\
\hline $\mathrm{I} 062^{(2)}$ & 0,98 & 0,15 & 0,12 & 0,12 & & & Tenho dificuldades em convencer as pessoas a me seguirem. \\
\hline I063 & 2,18 & 0,22 & $-1,30$ & 0,07 & 1,09 & 5,40 & $\begin{array}{l}\text { Sou capaz de estimular as pessoas a realizarem tarefas para as } \\
\text { quais estão desmotivadas. }\end{array}$ \\
\hline I064 & 1,47 & 0,18 & $-1,73$ & 0,14 & 0,73 & 4,55 & $\begin{array}{l}\text { Ajo de forma a motivar as pessoas e manter alto o moral em } \\
\text { qualquer situação. }\end{array}$ \\
\hline I065 & 2,47 & 0,22 & $-0,99$ & 0,05 & 1,24 & 6,01 & $\begin{array}{l}\text { Sei quais as palavras e ações adequadas para estimular as } \\
\text { pessoas. }\end{array}$ \\
\hline I066 & 2,60 & 0,26 & $-1,36$ & 0,07 & 1,30 & 5,27 & Sei que sou capaz de liderar uma equipe e atingir metas. \\
\hline I067 & 2,42 & 0,23 & $-1,24$ & 0,06 & 1,21 & 5,52 & $\begin{array}{l}\text { Posso convencer pessoas a superar conflitos e atuar em equipe } \\
\text { objetivando alcançar determinado resultado. }\end{array}$ \\
\hline $\mathrm{I} 068^{(2)}$ & 0,31 & 0,08 & $-0,95$ & 0,28 & & & $\begin{array}{l}\text { Não acredito em persuasão, pois manda quem pode e obedece } \\
\text { quem tem juízo. }\end{array}$ \\
\hline
\end{tabular}


Apêndice A. Continuação...

\begin{tabular}{|c|c|c|c|c|c|c|c|}
\hline Código & $\mathbf{a}$ & Ea & b & $\mathbf{E b}$ & $\mathbf{a}^{*}$ & $\mathbf{b}^{*}$ & Descrição \\
\hline I069 $9^{(2)}$ & 0,82 & 0,19 & $-3,29$ & 0,63 & & & Não acredito em planejamento. \\
\hline $\mathrm{I} 070^{(2)}$ & 0,68 & 0,13 & $-1,27$ & 0,18 & & & Não preciso de planejamento, já tenho tudo anotado na cabeça. \\
\hline I071 & 1,80 & 0,17 & $-0,74$ & 0,05 & 0,90 & 6,52 & Não consigo fazer nada sem um planejamento bem detalhado. \\
\hline I072 & 3,32 & 0,27 & $-0,92$ & 0,03 & 1,66 & 6,15 & $\begin{array}{l}\text { Defino onde quero chegar e detalho todos os passos que devo } \\
\text { seguir. }\end{array}$ \\
\hline I073 & 1,51 & 0,30 & $-2,62$ & 0,37 & 0,76 & 2,76 & $\begin{array}{l}\text { Estabelecer prazos, quanto vai custar e quem vai ser } \\
\text { responsável é essencial para o sucesso de qualquer atividade- } \\
\text { empreendimento. }\end{array}$ \\
\hline I074 & 1,04 & 0,18 & $-2,54$ & 0,33 & 0,52 & 2,92 & Quem não consegue planejar suas atividades tende a fracassar. \\
\hline $\mathrm{I} 075$ & 2,12 & 0,20 & $-1,06$ & 0,06 & 1,06 & 5,89 & $\begin{array}{l}\text { Só sei se estou acertando se tiver um planejamento das minhas } \\
\text { atividades. }\end{array}$ \\
\hline I076 & 1,08 & 0,15 & $-0,84$ & 0,09 & 0,54 & 6,32 & Eu só acredito em planejamento flexível, que possa ser alterado. \\
\hline I077 & 1,32 & 0,24 & $-2,44$ & 0,32 & 0,66 & 3,13 & Não me satisfaz fazer as coisas mal feitas. \\
\hline $\mathrm{I} 078^{(2)}$ & 0,62 & 0,15 & $-3,23$ & 0,64 & & & $\begin{array}{l}\text { Acredito que o consumidor não se importa de comprar produtos } \\
\text { ruins. }\end{array}$ \\
\hline I079 & 2,49 & 0,28 & $-1,46$ & 0,08 & 1,25 & 5,08 & Minhas expectativas para comigo mesmo são sempre altas. \\
\hline $\mathrm{I} 080^{(2)}$ & 0,59 & 0,14 & $-3,13$ & 0,62 & & & Não me importo se as pessoas fazem as coisas mal feitas. \\
\hline $\mathrm{I} 081^{(2)}$ & 0,73 & 0,16 & $-2,71$ & 0,47 & & & Deixar de atender compromissos para mim é uma coisa normal. \\
\hline I082 & 1,66 & 0,22 & $-1,70$ & 0,14 & 0,83 & 4,60 & $\begin{array}{l}\text { Se eu quiser vencer tenho que fazer as coisas melhor do que os } \\
\text { outros. }\end{array}$ \\
\hline $\mathrm{I} 083^{(2)}$ & 0,98 & 0,19 & $-2,49$ & 0,37 & & & $\begin{array}{l}\text { Quem fabrica coisas sem qualidade diminui suas chances de } \\
\text { lucro. }\end{array}$ \\
\hline I084 & 2,51 & 0,32 & $-1,70$ & 0,11 & 1,25 & 4,60 & Busco qualidade em tudo, desde o que faço até o que compro. \\
\hline I085 & 1,22 & 0,21 & $-2,18$ & 0,26 & 0,61 & 3,63 & $\begin{array}{l}\text { Quem vende coisas sem qualidade diminui suas chances de } \\
\text { sucesso. }\end{array}$ \\
\hline I086 & 1,33 & 0,16 & $-0,75$ & 0,07 & 0,67 & 6,51 & Quem não arrisca não petisca, portanto eu arrisco. \\
\hline $\mathrm{I} 087^{(1)}$ & & & & & & & $\begin{array}{l}\text { Não me sinto a vontade para arriscar meu patrimônio em uma } \\
\text { oportunidade de negócio. }\end{array}$ \\
\hline I088 & 1,59 & 0,18 & $-1,02$ & 0,07 & 0,80 & 5,96 & Quando posso eu corro riscos planejados. \\
\hline I089 & & & & & & & Acredito ser possível fazer negócios sem correr riscos. \\
\hline I090 & 1,96 & 0,21 & $-1,13$ & 0,07 & 0,98 & 5,74 & Calculo sempre os riscos que corro. \\
\hline I091 & 1,57 & 0,18 & $-1,14$ & 0,08 & 0,79 & 5,72 & Com relação a riscos eu sei até onde posso ir. \\
\hline $\mathrm{I} 092^{(2)}$ & 0,79 & 0,14 & $-1,76$ & 0,24 & & & Eu não gosto de riscos desnecessários. \\
\hline $\mathrm{I}_{093}^{(1)}$ & & & & & & & Sinto que sou ousado em relação a riscos, sejam lá quais forem. \\
\hline I094 & 2,11 & 0,28 & $-1,76$ & 0,13 & 1,06 & 4,47 & $\begin{array}{l}\text { Para então tomar uma decisão procuro antes saber qual é a } \\
\text { amplitude dos riscos que corro. }\end{array}$ \\
\hline I095 & & & & & & & Risco é risco, eu tenho muito receio de arriscar \\
\hline I096 & 2,29 & 0,21 & $-1,00$ & 0,05 & 1,15 & 6,01 & $\begin{array}{l}\text { Sou capaz de estabelecer rede de relações e utilizá-la para } \\
\text { alcançar meus próprios objetivos. }\end{array}$ \\
\hline I097 & 1,04 & 0,15 & $-1,15$ & 0,12 & 0,52 & 5,71 & $\begin{array}{l}\text { Acredito ser impossível atingir objetivos sem que se possua uma } \\
\text { boa rede de relacionamentos. }\end{array}$ \\
\hline $\mathrm{I} 098^{(2)}$ & 0,86 & 0,15 & $-1,83$ & 0,24 & & & $\begin{array}{l}\text { Ter a quem recorrer em busca de auxílio é crucial para o sucesso } \\
\text { de qualquer pessoa. }\end{array}$ \\
\hline I099 & 1,64 & 0,19 & $-1,57$ & 0,11 & 0,82 & 4,86 & $\begin{array}{l}\text { Procuro estabelecer uma boa rede de relacionamentos com } \\
\text { conhecidos, amigos e pessoas que possam me ser úteis. }\end{array}$ \\
\hline $\mathrm{I} 100$ & 1,78 & 0,20 & $-1,50$ & 0,10 & 0,89 & 5,00 & $\begin{array}{l}\text { Procuro manter contato constante com as pessoas de minha rede } \\
\text { de relações. }\end{array}$ \\
\hline $\mathrm{I} 101^{(2)}$ & 0,56 & 0,13 & $-2,67$ & 0,50 & & & $\begin{array}{l}\text { Não preciso ter rede de relações, pois, sou capaz de resolver } \\
\text { sozinho os meus problemas. }\end{array}$ \\
\hline $\mathrm{I} 102$ & 2,11 & 0,23 & $-1,56$ & 0,10 & 1,06 & 4,87 & $\begin{array}{l}\text { Tenho como manter contato fácil com as pessoas de minha rede } \\
\text { de relações. }\end{array}$ \\
\hline I103 & 2,06 & 0,28 & $-2,04$ & 0,17 & 1,03 & 3,91 & $\begin{array}{l}\text { Sempre que posso procuro atender as solicitações que me fazem } \\
\text { as pessoas de minha rede de relações. }\end{array}$ \\
\hline
\end{tabular}


Apêndice B. Níveis e itens âncoras.

\begin{tabular}{|c|c|c|c|}
\hline $\begin{array}{c}\text { Potencial } \\
\text { Empreendedor } \\
\theta^{*}\end{array}$ & Âncora & Código & Descrição \\
\hline \multirow[t]{2}{*}{$4^{(1)}$} & QA & $\mathrm{I} 074$ & Quem não consegue planejar suas atividades tende a fracassar. \\
\hline & QA & I077 & Não me satisfaz fazer as coisas mal feitas. \\
\hline \multirow{7}{*}{5} & QA & I021 & $\begin{array}{l}\text { Gosto de realizar meus trabalhos de forma correta e dentro dos prazos } \\
\text { estabelecidos. }\end{array}$ \\
\hline & A & I030 & Quando estou em determinado ramo eu tenho que aprender tudo sobre ele. \\
\hline & QA & I053 & Quando levo um tombo levanto e continuo. \\
\hline & QA & I055 & Entendo que os obstáculos existem para serem superados. \\
\hline & A & I057 & Busco, de forma permanente, atingir meus objetivos. \\
\hline & QA & I094 & $\begin{array}{l}\text { Para então tomar uma decisão procuro antes saber qual é a amplitude dos } \\
\text { riscos que corro. }\end{array}$ \\
\hline & QA & I103 & $\begin{array}{l}\text { Sempre que posso procuro atender as solicitações que me fazem as pessoas de } \\
\text { minha rede de relações. }\end{array}$ \\
\hline \multirow{17}{*}{6} & QA & I002 & Acredito na minha capacidade de resolver as coisas que me desafiam. \\
\hline & QA & I010 & Costumo verificar se as coisas estão acontecendo como planejei. \\
\hline & QA & I016 & $\begin{array}{l}\text { Acredito que as pessoas que não exercem algum tipo de controle sobre suas } \\
\text { vidas tendem ao fracasso. }\end{array}$ \\
\hline & QA & I029 & Tenho ânsia de aprender para poder enfrentar novos desafios. \\
\hline & QA & I031 & Quero saber cada vez mais, pois só assim eu saio na dianteira. \\
\hline & A & I036 & Sei onde pretendo chegar e o quanto pretendo alcançar. \\
\hline & QA & I043 & Tenho convicção que vou alcançar meus objetivos e metas. \\
\hline & QA & I044 & Vivo em estado de alerta para alguma oportunidade que me possa surgir. \\
\hline & QA & I046 & Creio sinceramente que as oportunidades estão aí para serem identificadas. \\
\hline & QA & I048 & Gosto de me informar sobre as necessidades das pessoas. \\
\hline & QA & $\mathrm{I} 050$ & Percebo as necessidades dos outros e como elas podem ser satisfeitas. \\
\hline & A & I058 & Quando cometo um erro de planejamento, redefino as coisas e vou em frente. \\
\hline & QA & I063 & $\begin{array}{l}\text { Sou capaz de estimular as pessoas a realizarem tarefas para as quais estão } \\
\text { desmotivadas. }\end{array}$ \\
\hline & A & I066 & Sei que sou capaz de liderar uma equipe e atingir metas. \\
\hline & QA & I067 & $\begin{array}{l}\text { Posso convencer pessoas a superar conflitos e atuar em equipe objetivando } \\
\text { alcançar determinado resultado. }\end{array}$ \\
\hline & A & I079 & Minhas expectativas para comigo mesmo são sempre altas. \\
\hline & QA & $\mathrm{I} 100$ & Procuro manter contato constante com as pessoas de minha rede de relações. \\
\hline \multirow{14}{*}{7} & QA & I001 & Sou eu quem controla a minha vida. \\
\hline & QA & I008 & $\begin{array}{l}\text { Considero-me autônomo e capaz de enxergar quais os melhores rumos para a } \\
\text { minha vida. }\end{array}$ \\
\hline & QA & I012 & Costumo fazer anotações e manter registros das minhas ações. \\
\hline & QA & I037 & O que eu pretendo alcançar está claramente definido. \\
\hline & QA & I039 & Eu sei determinar claramente quais são meus objetivos e metas. \\
\hline & A & I041 & Sou capaz de traçar um rumo e estabelecer os ganhos que vou ter no final. \\
\hline & A & I042 & Sei que posso definir meus rumos de curto, médio e longo prazos. \\
\hline & QA & I045 & Eu procuro fazer as coisas antes dos outros para sair na frente. \\
\hline & QA & I051 & $\begin{array}{l}\text { Sinto me capaz de identificar oportunidades de negócios e sair lucrando com } \\
\text { isso. }\end{array}$ \\
\hline & QA & I061 & Tenho formas de convencer as pessoas a mudarem de opinião. \\
\hline & A & I065 & Sei quais as palavras e ações adequadas para estimular as pessoas. \\
\hline & A & I072 & Defino onde quero chegar e detalho todos os passos que devo seguir. \\
\hline & QA & I088 & Quando posso eu corro riscos planejados. \\
\hline & QA & I096 & $\begin{array}{l}\text { Sou capaz de estabelecer rede de relações e utilizá-la para alcançar meus } \\
\text { próprios objetivos. }\end{array}$ \\
\hline $8^{(1)}$ & QA & $\mathrm{I} 038$ & Em minha opinião metas são coisas que posso quantificar. \\
\hline $9^{(1)}$ & QA & I060 & Orgulho-me de persuadir as pessoas a fazerem o que eu quero. \\
\hline
\end{tabular}

(1) nível não utilizado para interpretação da escala. 